\title{
Preparation of Soybean Oil Corn Starch Ester by using Immobilized Lipase
}

\author{
Zhengyang Wang ${ }^{1, a}$, Jiaying Xin ${ }^{1, b^{*}}$, Luoyun Zheng ${ }^{1, c}$, \\ Quanhui $\mathrm{Li}^{1, \mathrm{~d}}$ and Lirui Sun ${ }^{1, \mathrm{e}}$ \\ ${ }^{1}$ Key Laboratory for Food Science and Engineering, Harbin University of Commerce, China \\ a306224963@qq.com, bxinjiayingvip@163.com, '506637547@qq.com, \\ d1023281117@qq.com, ${ }^{\mathrm{e}} 578622848 @ q q . c o m$
}

\begin{abstract}
Keywords: Soybean oil corn starch ester; Novozym 435 lipase; Solvent-free system; Substituting degree.
\end{abstract}

\begin{abstract}
The soybean oil starch ester was synthesized by using Novozym435 lipase as biocatalyst, corn starch and soybean oil as substrate in solvent-free system. In order to improve the reaction activity of starch, the corn starch was pretreated using $\mathrm{NaOH} / \mathrm{Urea} / \mathrm{H} 2 \mathrm{O}$ solution. The optimum pretreatment reaction conditions of enzymatic esterification of soybean oil with pretreatment starch were water activity $<0.01$, reaction temperature was $60^{\circ} \mathrm{C}$, reaction time was $30 \mathrm{~h}$, the ratio of soybean oil to pretreatment starch was $6(\mathrm{w} / \mathrm{w})$ and the amount of lipase was $7 \%$. Under this condition the degree of substitute of soybean oil with pretreatment starch was 0.0302 . The solubility, emulsifying and freeze-thawing stability of soybean oil starch ester increased with the increase of its degree of substitute, but the transparency of soybean oil starch ester decreased with its degree of substitute. The transparency of soybean oil starch ester was improved in the presence of sucrose, but decreased in the presence of sodium chloride and citric acid.
\end{abstract}

\section{Introduction}

The importance of polyunsaturated fatty acids (PUFAs) in human nutrition and disease prevention has been and still is one of the major issues for the neutraceutical and pharmaceutical industries [1]. Over the last few decades, starch has been modified by various methods to achieve functionalities suitable for various industrial applications. Basically there are four kinds of modifications; chemical, physical, enzymatical and genetical[2].Selected edible oils, such as flaxseed and fish liver oils contain polyunsaturated fatty acids(PUFAs), which have important functional and physiological roles in human diets. PUFAs are widely recognized in the modulation of risk of a variety of diseases including cardiovascular, immunological, cancer, visual impairment and memory loss [3]. However, due to their high content of PUFAs, these oils are susceptible to oxidation producing off-flavors and potentially harmful radical products [4]. It is well known that enzyme-catalyzed ester synthesis is thermodynamically unfavorable in conventional aqueous media. A lot of methods have been developed to facilitate the formation of ester bonds over their hydrolysis. One approach is to replace water with an organic solvent to favor synthesis under restricted water conditions [5]. Over the last few decades, starch has been modified by various methods to achieve functionalities suitable for various industrial applications. Basically there are four kinds of modifications; chemical, physical, enzymatical and genetical. A number of review articles on the subject of starch modification are available [6-8].

Materials and methods

\section{Preparation of Soybean Oil Corn Starch Ester}

Synthesis of Soybean Oil Corn Starch Ester. The pretreatment of 1G starch (Gan Ji), soybean oil and lipase had been placed in the sealed container with 3 molecular sieve in 2 days 
Dried flask had been placed under $60{ }^{\circ} \mathrm{C}$ oil bath, added soybean oil, with magnetic stirring, to which add pretreated starch, and still had been stirring.Then we had get mixed homogeneous slurry, and adding lipase to esterification reaction at a constant temperature.

After a certain period of time, the $75^{\circ} \mathrm{C}$ heat ethanol had been washed two times and placed in an oven whose temperature is $75{ }^{\circ} \mathrm{C}$ to dry and crush. Then we had get the finished product and placed it in the sealed bag in $105{ }^{\circ} \mathrm{C}$ after constant weight

\section{Single Factor Experiment of the Preparation of Soybean Oil from Corn Starch}

Effect of enzyme addition on the degree of substitution. 1g pretreated starch (dry basis) had been dealed with 3 A molecular.

Sieve to balance Water activity. The reaction temperature had been $60^{\circ} \mathrm{C}$ and the reaction time had been $12 \mathrm{~h}$. The quality ratio of pretreated corn starch and soybean oil had been 1:5. $0.6 \mathrm{~g}$ of $3 \mathrm{~A}$ molecular sieve had been added when they are reacted.Under this reaction conditions, the effect of the addition of different lipase $(1 \%, 3 \%, 5 \%, 7 \%)$ on the degree of substitution of starch ester had been investigated.

Effect of reaction temperature on the degree of substitution. With the certained added amount of the most suitable lipase, $1 \mathrm{~g}$ of pretreated starch (dry basis) had been added with 3A molecular sieve to balance water activity. The reaction time had been $12 \mathrm{~h}$. The quality ratio of pretreated corn starch and soybean oil had been 1:5. 0.6 g 3A molecular Sieve had been added when they are reacted.Under this reaction conditions, the effect of different temperature $\left(55^{\circ} \mathrm{C}, 60^{\circ} \mathrm{C}, 65^{\circ} \mathrm{C}, 70^{\circ} \mathrm{C}\right)$ on the degree of substitution of starch ester had been investigated.

Effect of quality ratio of pretreated corn starch and soybean oil on the degree of substitution. With the certained added amount of the most suitable lipase and the most suitable reaction temperature, $1 \mathrm{~g}$ pretreated starch (dry basis) had been added with $3 \mathrm{~A}$ molecular sieve to balance water activity. The reaction time had been $12 \mathrm{~h}$. $0.6 \mathrm{~g}$ of $3 \mathrm{~A}$ molecular sieve had been added when they are reacted.Under this reaction conditions, the effect of different quality ratio of pretreated corn starch and soybean oil

$(1: 4,1: 5,1: 6,1: 7,1: 8)$ on the degree of substitution of starch ester had been investigated.

Effect of reaction time on the degree of substitution. With the certained quality ratio of pretreated corn starch and soybean oil, the added amount of the most suitable lipase and the most suitable reaction temperature, $1 \mathrm{~g}$ pretreated starch (dry basis) had been added with $3 \mathrm{~A}$ molecular sieve to balance water activity. $0.6 \mathrm{~g}$ of $3 \mathrm{~A}$ molecular sieve had been added when they are reacted. Under this reaction conditions, the effect of different reaction time $(12 \mathrm{~h}, 24 \mathrm{~h}, 36 \mathrm{~h}, 48 \mathrm{~h})$ on the degree of substitution of starch ester had been investigated.

\section{Characterization and Analysis Methods}

Determination of the degree of substitution. Take $0.03 \mathrm{~g}$ dried to constant weight of soybean oil corn starch ester sample in $50 \mathrm{~mL}$ of triangular reaction bottle, to which is added with $0.5 \mathrm{~mL}$ of DMSO. The sample was fully dissolved, then added to the reaction flask with $1 \mathrm{~mL}$ of $0.07 \mathrm{~mol} / \mathrm{L}$ sodium methoxide methanol solution. The reaction flask is placed in a constant temperature oil bath of $70{ }^{\circ} \mathrm{Cand}$ the reflux $1 \mathrm{~h}$ is condensed. After the end of the reaction, cooled to room temperature, added $1 \mathrm{~mL}$ of deionized water and $1 \mathrm{~mL}$-heptane and placed on a magnetic stirrer, stirred vigorously $1 \mathrm{~min}$. Still stratification, mixed fatty acid methyl esters in the extraction of the supernatant. Take supernatant liquid of $1 \mu \mathrm{L}$ sample was analyzed by gas chromatographic external standard method[5].

External standard: $3.373 \times 10-4 \mathrm{~mol} / \mathrm{L}$ of oleic acid methyl ester.

Chromatographic column: silica capillary column $(30 \mathrm{~m} \times 0.32 \mathrm{~mm} \times 0.25 \mu \mathrm{m})$, the column temperature is $220^{\circ} \mathrm{C}$, the inlet temperature is $250^{\circ} \mathrm{C}$, the detector temperature is $260^{\circ} \mathrm{C}$ [6].

Degree of substitution: $\mathrm{DS}=162 \mathrm{n} / \mathrm{m}-(\mathrm{m} 1-\mathrm{mH} 2 \mathrm{O})$

Type : DS-The number of polysaccharide monomers substituted carboxyl average; 162-The molecular weight of the glucopyranose residues,162; n-The amount of starch, which is replaced by fatty acid in soybean oil,moL; $\mathrm{m}$-The sample quality, $0.03 \mathrm{~g} ; \mathrm{m} 1$-The starch quality replaced by fatty acid,g; mH2O-Replace the quality of off water,g. 
SEM analysis. Dissolved the powder sample in deionized water and applied to the sample holder. The sample holder is placed in an ion sputtering apparatus, and a layer of 10nm thick gold film is deposited on the surface of the sample. The electron microscope was used to observe and photograph under different magnification.

infrared spectra analysis. Take $1 \mathrm{~g}$ sample (dry basis), into the $100 \mathrm{~mL}$ beaker, add $50 \mathrm{~mL} 60{ }^{\circ} \mathrm{C}$ volume fraction of $95 \%$ ethanol halved $30 \mathrm{~min}$, then moved to NO.3 sand core funnel, with $60{ }^{\circ} \mathrm{C}$ volume fraction of $95 \%$ ethanol rinsed thoroughly $24 \mathrm{~h}$ after drying at $50{ }^{\circ} \mathrm{C}$. The treated samples and potassium bromide were placed in a dryer with a certain proportion to be mixed with a certain proportion, and the changes of starch functional groups before and after esterification were investigated by Fourier transform infrared spectroscopy.

\section{Results}

Results and Analysis of Soybean Oil Corn Starch Ester Prepared Single Factor Experiments.

Influence of Enzyme Addition on the Degree of Substitution. The lipase addtion was 1\%, 3\%, $5 \%, 7 \%$, respectively, reaction temperature was $60{ }^{\circ} \mathrm{C}$, reaction time was $12 \mathrm{~h}$. The mass ratio of pre-starch and soybean oil was $1: 5.0 .6 \mathrm{~g}$ of $3 \AA$ molecular sieves were added to balance the water activity

Fig 1 showed that the degree of substitution ( $\mathrm{DS}=0.0017$ ) was maximum when the enzyme addition was 5\%. After enzyme addition exceeded 5\%, the substitution degree was gradually decreased, which might be the occurrence of lipase agglomeration which influenced the contact of substrate and lipase activity center. Also, with the amount of enzyme used increasing, the viscosity of the reaction system was increasing accordingly. Increasing shear agitation caused the destruction of immobilized enzyme morphology, which influenced the enzyme activity. So the degree of substitution was reduced. Therefore the optimum enzyme addition was $5 \%$.

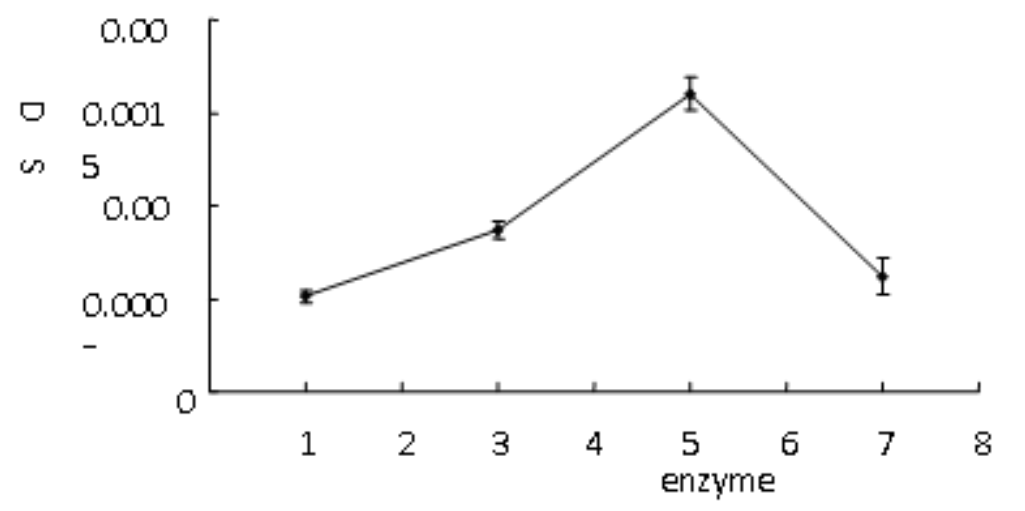

Figure 1. The effect of enzyme addition on the degree of substitution of starch ester 
Influence of Reaction Temperature on the Degree of Substitution. The reaction temperature was $55^{\circ} \mathrm{C}, 60^{\circ} \mathrm{C}, 65^{\circ} \mathrm{C}, 70^{\circ} \mathrm{C}$, respectively, reaction time was $12 \mathrm{~h}$. The mass ratio of pre-starch and soybean oil was $1: 5.0 .6 \mathrm{~g}$ of $3 \AA$ molecular sieves were added to balance the water activity.

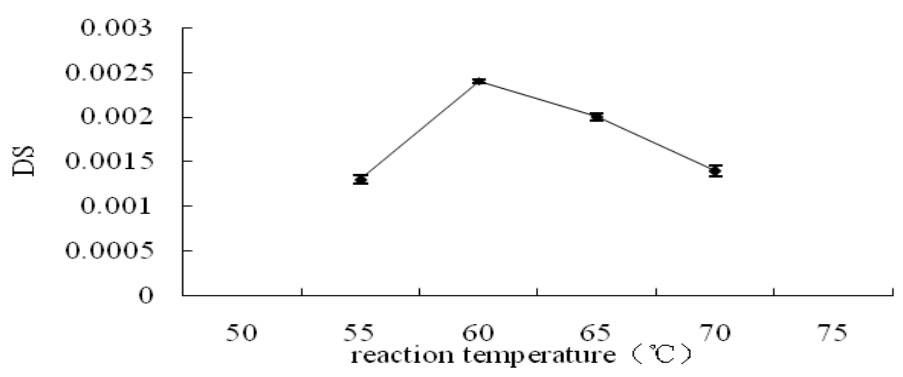

Figure 2. Effect of reaction temperature on the degree of substitution of starch ester

Fig. 2 showed that the degree of substitution ( $\mathrm{DS}=0.0024)$ was maximum when the reaction temperature was $60^{\circ} \mathrm{C}$, exceeded this temperature the degree of substitution decreased. Immobilized lipase Novozym 435 used in this test had a high reactivity in the range of $55 \sim 75^{\circ} \mathrm{C}$, which might be overheated and partial inactivation of the enzyme. At the same time the high temperature made the reaction equilibrium move to reverse direction, hydrolyze the generated starch ester again. So the selected reaction temperature was $60^{\circ} \mathrm{C}$ in the following reaction.

Influence of the Ratio of the Pre-corn Starch and Soybean Oil on the Degree of Substitution. The ratio of pre-corn starch and soybean oil added was 1: 5, 1:4, 1:6, 1:7, respectively, reaction time was $12 \mathrm{~h}$, reaction temperature was $60{ }^{\circ} \mathrm{C}$, the lipase addition was $5 \%, 0.6 \mathrm{~g}$ of $3 \AA$ molecular sieves were added to balance the water activity. Fig. 3 showed, that the degree of substitution ( $\mathrm{DS}=0.003$ ) was maximum when the ratio of pre-starch and soybean oil mass was 1:6. after the mass ratio exceeded 1:6, the degree of substitution decreased obviously. In the absence of solvent system, soybean oil was not only a reaction substrate, but also played a role as solvent. Re- duced the viscosity of the reaction system greatly, was beneficial to the movement of esterification reaction direction. But when the amount of soybean oil used was too high, the contact chance of hydroxyl groups on starch and lipase activity center was reduced, which caused the decrease of the degree of substitution. Therefore the selected mass ratio of starch and soybean oil ratio was 1:6.

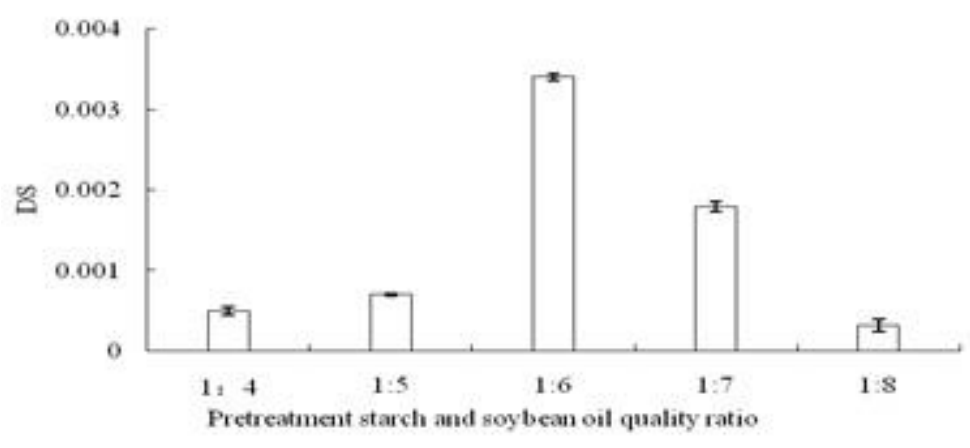

Figure 3. Effect of pre treated starch and soybean oil quality on the degree of substitution of starch ester

Influence of the Reaction Temperature on the Degree of Substitution. Reaction time was $6 \mathrm{~h}, 12 \mathrm{~h}, 18 \mathrm{~h}, 24 \mathrm{~h}, 30 \mathrm{~h}$, reaction temperature was $60{ }^{\circ} \mathrm{C}$, the lipase addition was $5 \%$, the mass ratio of pre-corn starch and soybean oil was $1: 6,0.6 \mathrm{~g}$ of $3 \AA$ molecular sieves were added to balance the water activity 
Fig. 4 shows that the degree of substitution $(\mathrm{DS}=0.017)$ was maximum when reaction time was $24 \mathrm{~h}$. The degree of substitution of product decreased with the time extending. This was because during the reactor operating, prolonged agitation shearing made the immobilized enzyme come off from the carrier, and abrasion caused reduction of particle size which affected the stability of the immobilized enzyme, leading to the enzyme catalytic efficiency reduce, even enzyme inactivation. With the reaction time extending, the generated product was partially hydrolyzed, resulting in the degree of substitution decreasing. In summary, the best reaction time should be $24 \mathrm{~h}$.

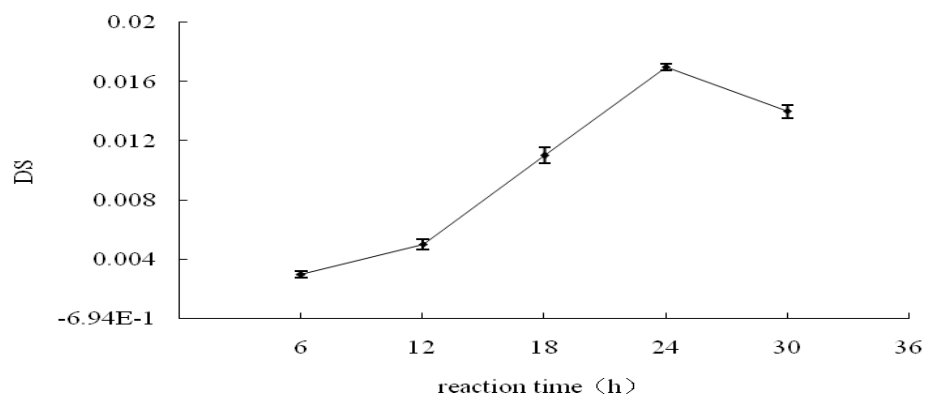

Figure 4. Effect of reaction time on the degree of substitution of starch ester

Scanning Electron Microscope Analysis. From the Fig. 5, it is clear that the pre-processing starch particle diameter in $500 \sim 1000 \mathrm{~nm}$ and particle surface is uneven. Appearance of high oil corn starch ester is granular, but the particles become smaller, the average particle diameter is in $300 \sim 800$ $\mathrm{nm}$, but because of fatty acids in soybean oil is mainly long chain fatty acid, the infiltration of long chain fatty acid chains to starch granules reduce the agglomeration of starch granules. So the esters of starch granule surface will appear uneven.
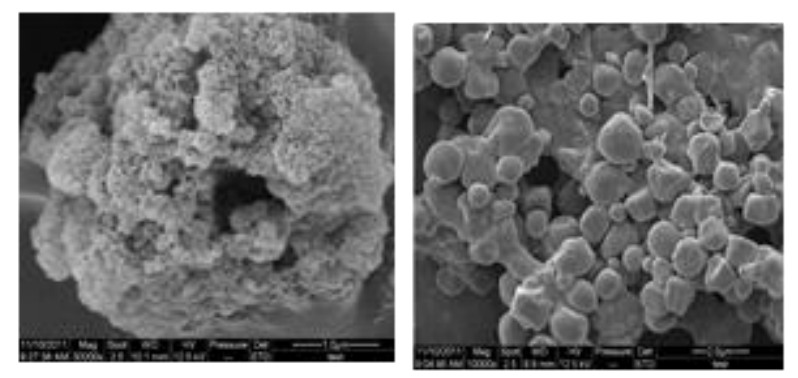

Figure 5. Scanning electron microscope of pretreated starch (A) and soybean oil corn starch (B)

Infrared Spectrum Analysis. Infrared spectrum analysis is an important tool for analysis of starch and other organic polymer material, which uses the selective absorption of organic functional groups in the mid-infrared region, it can qualitative analyze the organic compounds, in particular functional groups. Infrared spectrogram of corn starch and pre-starch were basically similar, but its -OH stretching vibration peak was wider than the original starch significantly.Soybean oil starch esters had typical ester bond characteristic absorption peak at $1725 \sim 1750 \mathrm{~cm}-1$, which explained that the degree of substitution of starch esters prepared were already within the scope of the equipment testing, thus proved that soybean oil fatty acid substituted starch hydroxyl groups.

\section{Summary}

From the various factors that affected the degree of substitution of soybean oil corn starch ester showed that, the influence of reaction temperature on the esterification was biggest, followed was the amount of enzyme addition. When water activity $<0.01$, optimal condition of soybean starch esters preparation was $7 \%$ of enzyme addition, reaction time was $30 \mathrm{~h}$, substrate ratio was $1: 6$, temperature 
was $60{ }^{\circ} \mathrm{C}$. The degree of substitution of soybean oil starch ester prepared under these conditions was 0.0302 .

Appearance of soybean oil corn starch ester remained granular shape, and the shape was similar to corn starch. Starch particle size was smaller than the pre-treatment $(500 \sim 1000 \mathrm{~nm})$ relatively, was $300 \sim 800 \mathrm{~nm}$. Starch esters particle surface appeared uneven. Infrared spectrogram showed that pre-corn starch and corn starch were basiclly similar, but its hydroxyl stretching vibration peak wider than the original starch significantly, which indicated that hydroxyl groups were increased; and soybean oil starch ester had typical ester bonding characteristic absorption peak at $1725 \sim 1750 \mathrm{~cm}-1$, which proved that soybean oil fatty acid substituted starch hydroxyl groups due to the esterification..

\section{References}

[1] Kris-Etherton P M, Taylor D S, Yu-Poth S, Huth P, Moriarty K, Fishell V, Hargrove R L, Guixiary Z and Etherton T D. Polyunsaturated fatty acids in the food chain in the United States, Am J Clinical Nutr. 71(2000)1795-1885.

[2] Jobling S. mproving starch for food and industrial applications, Current Opinion in Plant Biology. 7(2004)210-218.

[3] Riediger N, Othman R, Suh M and Moghadasian M, A systemic review of the roles of n3 fatty acids in health and disease, Am Diet Assoc. 109(2009)668-679.

[4] Roche H M. Unsaturated fatty acids, Proceed Nutr Soc. 58.397-401.

[5] Klibanov AM. Improving enzymes by using them in organic solvents, Nature, 6(2001) 241-246.

[6] Jobling S A, Jarman C, The M M, Holmberg N, Blake C \& Verhoeyen M E. Immunomodulation of enzyme f-unction in plants by single-domain antibody fragments, Nature Biotechnology. 21(2003)77-80.

[7] BeMiller J N. Starch modification: challenge sand prospects, Starch/Stärke. 49(1997)127-131.

[8] Tharanathan R N. Starch-value addition by modification, Critical Reviews in Food Science and Nutrition.45(2007)371-384.

[9] Alissandratos A, Baudendistel N, Hauer B, et al, Lipase-catalysed acylation of starch and determination of the degree of substitution by methanolysis and GC, BMC Biotech., 2010, pp. $10-16$.

[10] Jia-Ying Xin, Yan Wang, Tie Liu, Kai Lin, Le Chang and Chun-Gu Xia,Biosysthesis of Corn Starch Palmitate by Lipase Novozym 435,Inter.J. Mo. Sci.. 13(2012)7226-7236. 